\title{
ANALISIS SEBARAN Nepenthes spp. DI HUTAN KERANGAS CAGAR ALAM PADANG LUWAY DI KABUPATEN KUTAI BARAT
}

\author{
Sulistianto $^{1}$, Muhammad Sumaryono ${ }^{2}$, dan Ali Suhardiman ${ }^{2}$ \\ ${ }^{1}$ Program Magister Ilmu Kehutanan, Fakultas Kehutanan \\ Universitas Mulawarman. \\ ${ }^{2}$ Fakultas Kehutanan, Universitas Mulawarman, J1 Ki Hajar Dewantara Kampus Gunung \\ Kelua, Samarinda, Kalimantan Timur, Indonesia 75119, Indonesia. \\ E-mail: pijar_alief@yahoo.co.id
}

\begin{abstract}
ABSTRAK
Analisis Sebaran Nepenthes spp. Di Hutan Kerangas Cagar Alam Padang Luway Di Kabupaten Kutai Barat, Cagar Alam Padang dengan luas \pm 5.000 Ha Luway merupakan kawasan suaka alam yang karena keadaan alamnya mempunyai kekhasan/keunikan jenis tumbuhan dan/atau keanekaragaman tumbuhan seperti berbagai jenis anggrek dan Nepenthes spp. beserta gejala alam dan ekosistemnya berupa hutan kerangas dengan ciri khas lantai hutan berupa pasir (kersik) berwarna putih yang memerlukan upaya perlindungan dan pelestarian agar keberadaan dan perkembangannya berlangsung secara alami, secara administrasi berada di tiga kecamatan yaitu Melak, Damai dan Sekolaq Darat Kabupaten Kutai Barat. Pengelolaannya oleh Balai Konservasi Sumber Daya Alam (BKSDA) Kalimantan Timur. Penelitian ini dilakukan untuk mengetahui sebaran Nepenthes spp. dengan menggunakan indeks Morisita dan Nearest Neighbor Analysis serta untuk mengetahui potensinya dengan menggunakan metode analisa vegetasi. Berdasarkan hasil penelitian ini diketahui terdapat 3 (tiga) jenis Nepenthes yaitu N. Reinwardtiana hijau dan merah, $N$. Ampullaria dan N. Gracilis hijau dan merah, yang tersebar pada tiga lokasi penelitian yaitu di lokasi Kersik Luway ditemukan 137 individu N. Reinwardtiana yang tersebar di 10 (sepuluh) plot penelitian, di lokasi Kersik Mencege ditemukan 120 individu N. Ampullaria yang tersebar di 5 (lima) plot penelitian dan $N$. Gracilis di 2 (dua) plot penelitian serta di lokasi Kersik Serai ditemukan 80 individu N. Gracilis hijau pada 2 (dua) plot penelitian dan 162 individu $N$. Gracilis merah pada 8 plot penelitian. Dari Indek Nilai Penting (INP) diketahui dominasi tertinggi adalah $N$. Gracilis Merah sebesar 58,420 \% dan terendah adalah N. Gracilis Hijau yaitu 15,953 \%. Sedangkan hasil Indeks Morisita untuk semua jenis nepenthes di CA. Padang Luway adalah lebih dari 1 (Id $>1$ ) yang menunjukan pola penyebaran mengelompok, begitu pula hasil pengolahan data dengan menggunakan Nearest Neighbor Analysis dengan hasil mengelompok (Cluster).
\end{abstract}

Kata kunci : Cagar Alam Padang Luway, Sebaran, Nepenthes.

\begin{abstract}
Analysis of the Distribution of Nepenthes spp. in the Padang Luway Nature Reserve, West Kutai Regency. The Padang Nature Reserve with an area of $\pm 5,000$ Ha Luway is a nature reserve area which due to its natural conditions has specificity/uniqueness of plant species and/or plant diversity such as various types of orchids and Nepenthes spp. along with natural symptoms and ecosystems in the form of kerangas forest with distinctive characteristics of a white sand floor that requires protection and preservation so that its existence and development take place naturally, administratively in three sub-districts namely Melak, Damai and Sekolaq Darat West Kutai Regency. Management by the East Kalimantan Natural Resources Conservation Center (BKSDA). This study was conducted to determine the distribution of Nepenthes spp. by using the Morisita index and Nearest Neighbor Analysis and to determine their potential by using vegetation analysis methods. Based on the results of this study it was found that there were 3 (three) Nepenthes types, namely $N$. reinwardtiana green and red varian, $N$. ampullaria and $N$. gracilis green and red variant, which were scattered in three research locations, namely in the Kersik Luway location found 137 individuals $N$. reinwardtiana scattered in 10 (ten) research plots, 120 grains of $N$. ampullaria were scattered in the location of Kersik Mencege in 5 (five) research plots and $N$. gracilis in 2 (two) research plots and $80 \mathrm{~N}$. gracilis green
\end{abstract}


variant individuals were found in Kersik Serai. in 2 (two) research plots and $162 \mathrm{~N}$. gracilis red variant individuals in 8 research plots. From the Important Value Index (INP) it is known that the highest dominance is $N$. gracilis red variant which is $58.420 \%$ and the lowest is $N$. gracilis green variant which is $15.953 \%$. While the results of the Morisita Index for all types of Nephesthes in CA. Padang Luway is more than 1 $(\mathrm{Id}>1)$ which shows a clustered distribution pattern, as well as the results of data processing using the Nearest Neighbor Analysis with Clustering results.

Key words : Nature Reserve Padang Luway, distribution, Nepenthes.

\section{PENDAHULUAN}

Penampilan Nepenthes spp. sangat eksotis karena dari ujung daunnya muncul kantong dengan bentuk dan ukuran serta corak yang beragam. Tanaman yang tumbuh merambat ini juga disebut sebagai carnivorous plant atau tanaman pemakan daging, karena kantongnya yang eksotis itu sebetulnya adalah perangkap bagi hewan atau serangga. Hewan yang tergelincir masuk dalam kantong tidak dapat keluar lagi, dan inilah sumber nutrisi bagi Nepenthes spp. yang tumbuh liar di alam bebas.

Tanaman yang terdiri atas sedikitnya 103 spesies ini mempunyai keunikan karena hampir seluruhnya merupakan tanaman karnivora atau pemakan daging. Selain karnivora tanaman ini juga memiliki keunikan pada bentuk, ukuran, dan corak warna kantongnya sehingga tidak sedikit orang yang berlomba-lomba untuk memeliharanya sebagai tanaman hias. Dan akibatnya keberadaan Nepenthes spp. di habitat aslinya terancam kepunahan.

Tanaman yang dilindungi ini termasuk dalam CITES (Convention on International Trade of Endangered Species) terdapat dalam apendiks I dan II, tergolong hampir punah dan langka. Sedangkan di Indonesia, berdasarkan Peraturan Pemerintah Nomor 7 tahun 1999 tentang Pengawetan Jenis Tumbuhan dan Satwa, semua jenis Nepenthes sp. dilindungi di habitat aslinya. Nepenthes spp. dapat diperdagangkan jika berasal dari hasil penangkaran, bukan pengambilan dari habitat aslinya.

\section{METODA PENELITIAN}

\subsection{Tempat dan Waktu}

Penelitian dilaksanakan di kawasan Cagar Alam Padang Luway. Pada bulan Maret-Juli 2017.

\subsection{Bahan dan Alat}

Peta Penepatan Kawasan CA. Padang Luway Skala 1 : 50.000 tahun 2014 sesuai dengan Keputusan Menteri Kehutanan Nomor : SK. 1834/MenhutVII/KUH/2014, untuk mengetahui dan menentukan plot penelitian, roll meter untuk mengukur luas dan panjang transek, milimeter block, tali raffia untuk membuat petak penelitian, (Global Positioning System) GPS untuk menentukan koordinat, pita survei untuk menandai batas plot dan member nomor pada setiap individu vegetasi yang didata, kamera untuk mendokumentasikan gambar setiap jenis yang ditemui serta tallysheet dan alat tulis untuk mencatat data-data yang diambil di lapangan.

\subsection{Metode Penelitian}

Penelitian dilakukan pada tiga lokasi didalam kawasan CA. Padang Luway yaitu Kresil Luway, Kresik Mencege dan Kresik Seray, dengan membuat plot-plot penelitian pada tiap lokasi berupa petak tunggal dengan ukuran $20 \mathrm{~m} \times 100 \mathrm{~m}$ atau seluas $2.000 \mathrm{~m}^{2}$, kemudian dibuat jalur sejajar arah timur-barat dengan ukuran $10 \mathrm{~m} \mathrm{x}$ 
$100 \mathrm{~m}$. Pada tiap jalur dibuat petak ukur dengan ukuran $10 \mathrm{~m}$ x $10 \mathrm{~m}$.

Sebagaimana ilustrasi gambar berikut :

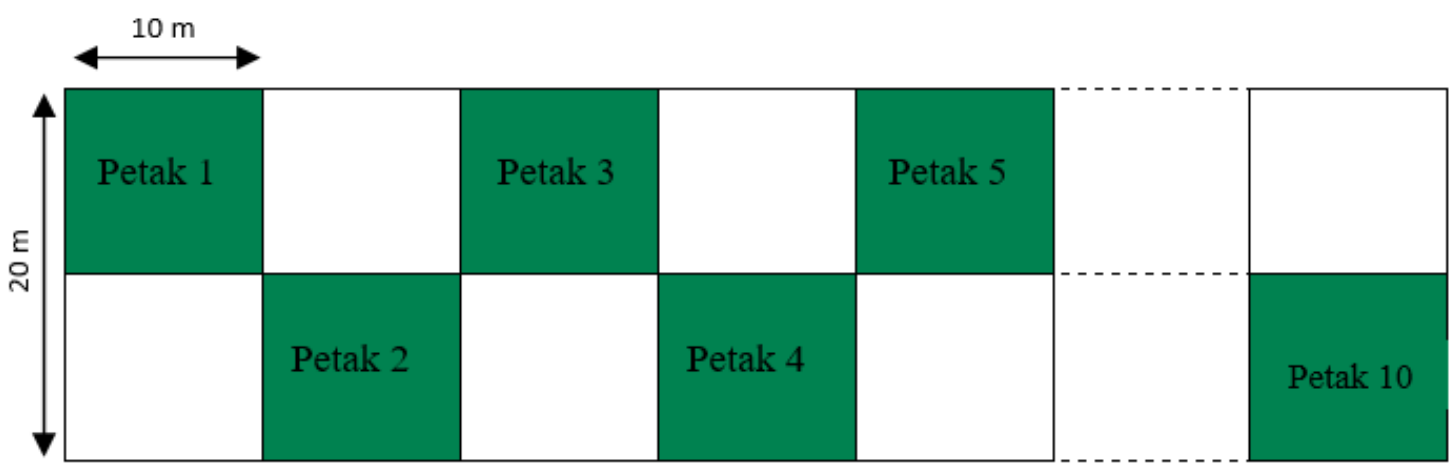

Gambar 1, Bentuk dan ukuran petak pengamatan

\subsubsection{Pengumpulan data primer}

Pengumpulan data primer dilakukan dengan cara pengamatan dan pencatatan pada petak-petak penelitian berupa melihat dan mengamati jenis-jenis Nepenthes spp. yang berada dalam plot yang telah dibuat, melakukan pencatatan dan dokumentasi jenis Nepenthes spp. dan vegetasi sekitar yang berada dalam plot yang telah dibuat, pengambilan titik koordinat Nepenthes spp. menggunakan GPS (global Posisitioning System) serta pengukuran jarak antar individu pada distribusi Nepenthes spp. yang tumbuh rapat.

\subsubsection{Pengumpulan data sekunder}

Adalah dengan melakukan studi literatur, yaitu dengan mengumpulkan data yang bersumber dari laporan hasil penelitian yang dilakukan pada lokasilokasi yang berbeda, hasil survey maupun buku dan artikel yang mengulas tentang jenis, habitat dan bioekologi Kantong Semar (Nepenthes spp), serta dengan melakukan pengumpulan data dengan melakukan wawancara kepada pihakpihak yang dapat memberikan informasi yang dibutuhkan pada penelitian ini.

\subsubsection{Pengolahan dan analisis data}

Dari hasil pengumpulan data penyebaran Nepenthes spp. dilapangan, kemudian data diolah dengan menggunakan rumusrumus sebagai berikut :

1. Analisa Vegetasi, menggunakan rumus menurut Soerianegara \& Indrawan (1988) :

Menghitung kerapatan individu (kerapatan) :

Kerapatan $(K)=\frac{\text { Jumlah individu suatu spesies }}{\text { Jumlah Seluruh plot pengamatan }}$

Menghitung sebaran jenis (frekuensi) :

Frekuensi $=\frac{\text { Jumlah }(\text { plot }) \text { terisi suatu spesies }}{\text { Banyaknya/jumlah seluruh plot }}$

Nilai Penting Jenis (NPJ) :

$\mathrm{NPJ}=\mathrm{KR}(\%)+\mathrm{FR}(\%)$

2. Indeks Morisita.

Dengan menggunakan rumus Indeks Morisita menurut Krebs (1999) Krebs (1999) yang dikutip oleh Jongjitvimol (2005), yaitu :

Menghitung nilai Indeks Morisita (Id)

$$
I d=n\left[\frac{\left(\Sigma x^{2}-\Sigma x\right)}{(\Sigma x)^{2}-\Sigma x}\right]
$$

Dimana :

$\mathrm{n}=$ jumlah petak pengamatan

$\mathrm{x}=$ jumlah individu pada setiap petak pengamatan 
Menghitung $\mathrm{Mu}$ dan $\mathrm{Mc}$, untuk menunjukan pola sebaran

$$
\mathrm{Mu}=\frac{\chi_{0,975}^{2}-n+\sum x_{i}}{\left(\sum x_{i}\right)-1}
$$

Dimana :

$\mathrm{Mu}=$ Indeks Morisita untuk pola sebaran seragam

$\not 0,975^{\circ}=$ Nilai chi square table dengan derajat bebas n-1 dan selang

Kepercayaan $97,5 \%$

$\mathrm{Mc}=\frac{\chi_{0,025}^{2}-n+\sum x_{i}}{\left(\sum x_{i}\right)-1}$

Dimana :

Mc $=$ Indeks Morisita untuk pola sebaran mengelompok

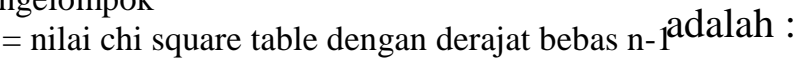

dan selang kepercayaan 2,5\%

Menghitung Standar Derajat Morisita, dengan menggunakan rumus :

$\mathrm{Ip}=0,5+0,5\left(\frac{I d-M c}{n-M c}\right) \quad$ jika Id
$\geq \mathrm{Mc}>1$

$\mathrm{Ip}=0,5\left(\frac{I d-1}{M c-1}\right)$

jika $\mathrm{Mc}>\mathrm{Id} \geq 1$

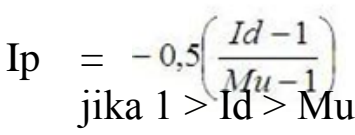

Ip $=-0,5+0,5\left(\frac{I d-M u}{I^{u}}\right)$
jika $1>\mathrm{Mu}>\mathrm{Id}^{u}$

Langkah terakhir adalah menentukan pola sebaran berdasarkan nilai Ip :

Jika Ip $<0$ maka pola sebarannya

Seragam.

Jika Ip $=0$ maka pola sebarannya Acak
Jika Ip $>0$ maka pola sebarannya Mengelompok

3. Nearest Neighbor Analysis

Dengan meneliti jarak antara setiap titik dan titik terdekat kemudian membandingkannya dengan nilai yang diharapkan untuk sampel acak poin dari pola CSR (complete spatial randomness).

Hipotesis nol CSR diuji menggunakan statistik $\mathrm{Z}$ (varian normal standar). Skor $\mathrm{Z}$ negatif menunjukkan pengelompokan; skor positif menunjukkan dispersi atau kemerataan. Adapun Statistik Z dihitung menggunakan rumus di bawah ini, (Anonim, 2016). Adapun rumus yang digunakan

Nearest Neighbor Analysis

$$
\bar{d}=\frac{\sum_{i=1}^{N} d_{i}}{N}
$$

Dimana $\mathrm{N}$ adalah jumlah poin, $\mathrm{d} i$ adalah jarak tetangga terdekat untuk titik i

Nilai yang diharapkan dari jarak tetangga terdekat dalam pola acak

$E\left(d_{i}\right)=0.5 \sqrt{\frac{A}{N}}+\left(0.0514+\frac{0.041}{\sqrt{N}}\right) \frac{B}{N}$

di mana A adalah area dan B adalah panjang area studi varians

$\operatorname{Var}(\bar{d})=0.070 \frac{A}{N^{2}}+0.037 B \sqrt{\frac{A}{N^{5}}}$

Statistic Z

$Z=\frac{\bar{d}-E\left(d_{i}\right)}{\sqrt{\operatorname{Var}(\bar{d})}}$ 
Semua data yang dperoleh, diolah dengan menggunakan tool Point Pattern Nearets Neighbor Analysis ArcGis.

\section{HASIL PENELITIAN DAN PEMBAHASAN}

Dari hasil penelitian yang dilakukan di kawasan Cagar Alam Padang Luway diketahui terdapat 3 (tiga) jenis Kantong Semar (Nepenthes spp.) yaitu $N$. Reinwardtiana dengan varian kantong berwarna hijau dan merah, $N$. Ampullaria, N. Gracilis dengan varian kantong berwarna hijau dan merah. Untuk lokasi 1 (Kersik Luway), terdapat $N$. Reinwardtiana dengan varian kantong berwarna hijau dan merah, sebagaimana gambar 2 dibawah ini.
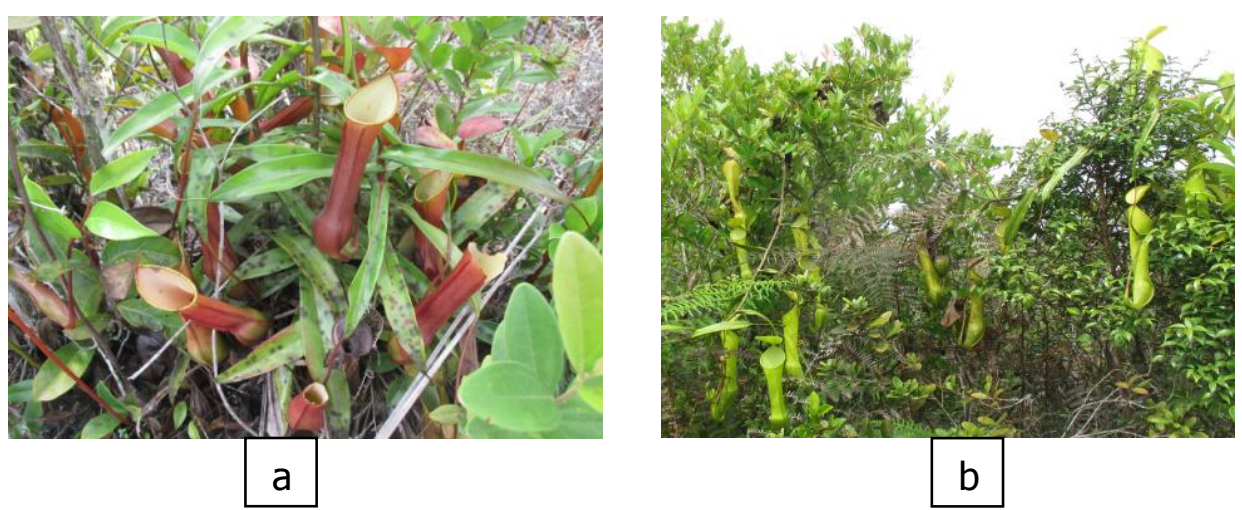

Gambar 2. Nepenthes reinwardtiana varian kantong warna merah (a), Nepenthes reinwardtiana varian kantong warna hijau (b).

Sedangkan untuk lokasi 2 (Kersik Mencege), terdapat $N$. Ampullaria dan $N$. gracilis dengan varian kantong berwarna

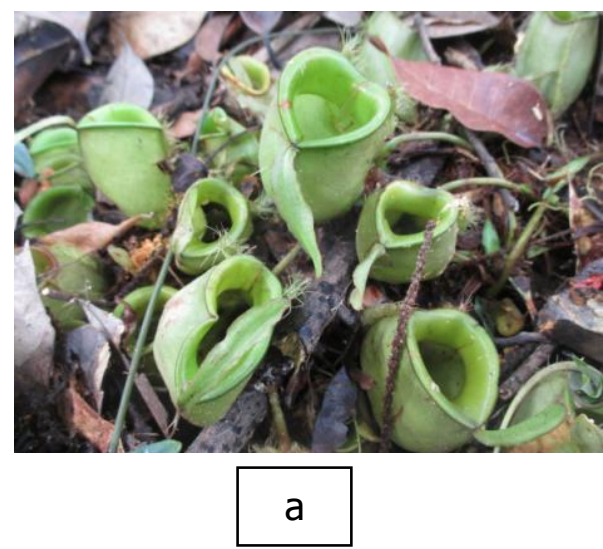

hijau, sebagaimana pada gambar 3 dibawah ini.

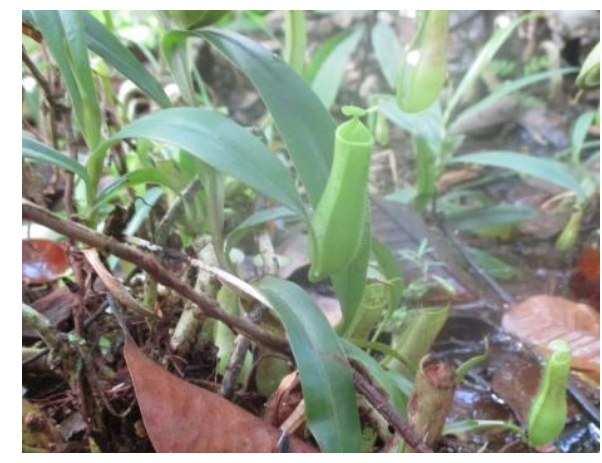

b

Gambar 3. Nepenthes ampullaria (a), Nepenthes gracilis (b). 
Kemudian untuk lokasi 3 (Kersik Seray), ditemukan N. Gracilis dengan dengan varian kantong berwarna hijau dan

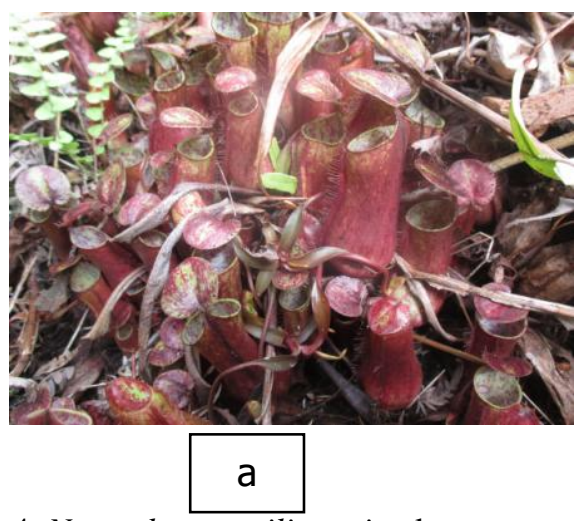

Gambar 4. Nepenthes gracilis varian kantong merah (a), Nepenthes gracilis varian kantor hijau (b).

\subsection{Indek Nilai Penting (INP)}

Indeks Nilai Penting (INP) adalah parameter kuantitatif yang dapat dipakai untuk menyatakan tingkat dominansi jenis-jenis dalam suatu komunitas tumbuhan. Jenis-jenis yang dominan (yang berkuasa) dalam suatu komunitas tumbuhan akan memiliki indeks nilai penting yang paling besar (Indriyanto, 2006). Selanjutnya menurut (Soegianto, 1994) Indeks Nilai Penting jenis tumbuhan pada suatu komunitas merupakan salah satu parameter yang merah, sebagaimana pada gambar 4 dibawah ini

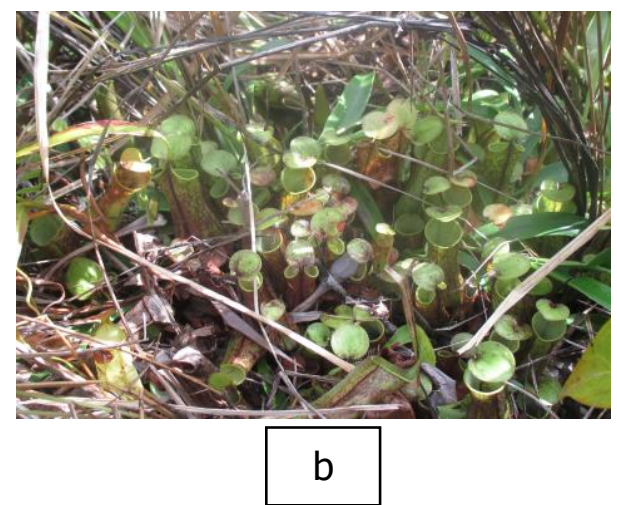

Tabel 1. Indek Nilai Penting (INP) Nepenthes spp. di CA. Padang Luway

\begin{tabular}{|c|c|c|c|c|c|c|c|}
\hline No. & Lokasi & $\begin{array}{l}\text { Nama } \\
\text { Ilmiah }\end{array}$ & K & $\mathrm{F}$ & $\begin{array}{l}\mathrm{KR} \\
(\%)\end{array}$ & $\begin{array}{l}\mathrm{FR} \\
(\%)\end{array}$ & INP \\
\hline \multirow[t]{2}{*}{1.} & $\begin{array}{l}\text { Kersik } \\
\text { Luway }\end{array}$ & $\begin{array}{l}\text { N.reinwardtiana } \\
\text { warna hijau }\end{array}$ & 0,026 & 0,333 & 16,46 & 30,30 & 46,759 \\
\hline & & $\begin{array}{l}\text { N.reinwardtiana } \\
\text { warna merah }\end{array}$ & 0,019667 & 0,300 & 12,45 & 27,27 & 39,720 \\
\hline \multirow[t]{2}{*}{2.} & $\begin{array}{l}\text { Kersik } \\
\text { mencege }\end{array}$ & N. ampurella & 0,031667 & 0,133 & 20,04 & 12,12 & 32,163 \\
\hline & & N.gracilis warna hijau & 0,018333 & 0,067 & 10,40 & 5,56 & 15,953 \\
\hline \multirow[t]{3}{*}{3.} & Kersik Seray & N.gracilis warna hijau & 0,026667 & 0,067 & 16,88 & 6,06 & 22,938 \\
\hline & & $\begin{array}{l}\text { N.gracilis warna } \\
\text { merah }\end{array}$ & 0,054 & 0,267 & 34,18 & 24,24 & 58,420 \\
\hline & \multicolumn{2}{|c|}{ Jumlah } & 0,177 & 1 & 100 & 100 & 200 \\
\hline
\end{tabular}


Dari Tabel 2 diketahui bahwa INP tertinggi adalah Nepenthes gracilis kantong merah yaitu sebesar 58, $420 \%$ di lokasi penelitian Kersik Seray, dan yang terendah adalah Nepenthes gracilis kantong hijau pada lokasi Kersik Mencege yaitu sebesar 15,953\%.

Besarnya nilai INP pada Nepenthes gracilis kantong merah dibanding dengan INP Nepenthes jenis lainnya dipengaruhi dengan kondisi lingkungan tempat tumbuh dan nilai kerapatan (K) yaitu sebesar 0,054 atau 54 tumbuhan per $\mathrm{m}^{2}$ dengan kerapatan relative (KR) 34,18\%. Besarnya nilai kerapatan (K) Nepenthes gracilis Merah juga banyak dipengaruhi oleh lokasi tempat tumbuh yaitu Kersik Seray. Menurut Dariana (2010), banyaknya jumlah individu sangat dipengaruhi oleh keadaan lingkungan yang sesuai untuk pertumbuhan dan perkembangan serta tersedianya biji. Pada lokasi Kersik Serai keadaan lebih terbuka dimana jarang ditemukan adanya pohon-pohon tinggi dan lebih didominasi oleh tanaman paku (Gleichenia spp), sehingga sinar matahari dapat langsung diterima oleh tanaman Nepenthes.

Menurut Clarke (2001), beberapa spesies dari Nepenthes mampu bertahan hidup pada penyinaran matahari penuh atau menyukai sinar matahari langsung. Nepenthes gracilis adalah jenis yang tumbuh cepat, umumnya hidup ditempat terbuka dan menjalar di pasir kwarsa hutan kerangas (Mansur, 2007).

\subsection{Indeks Morisita (Id)}

Setelah dilakukan pengolahan data dari hasil penelitian di CA. Padang Luway dengan menggunakan perhitungan Indeks Morisita, menunjukan bahwa tiga jenis Nepenthes yaitu Nepenthes reinwardtiana kantong berwarna hijau dan merah, Nepenthes ampurella, Nepentes gracilis kantong berwarna hijau dan merah memiliki pola penyebaran mengelompok, dengan nilai indek lebih dari 1 (Id>1) yang berarti pola penyebarannya mengelompok.

Pola penyebaran nepenthes dengan menggunakan Indeks Morisita dapat dilihat pada Tabel 2 berikut ini :

Tabel 3. Indeks Morisita Pola Sebaran Nepenthes spp. di CA.Padang luway

\begin{tabular}{|c|c|c|c|c|c|c|}
\hline No & Lokasi & Nama Ilmiah & Id & Mu & Mc & Ip \\
\hline \multirow[t]{2}{*}{1.} & \multirow[t]{2}{*}{ Kresik Luway } & $\begin{array}{l}\text { Nepenthes reinwardtiana } \\
\text { kantong hijau }\end{array}$ & 1,5784 & 0,9182 & 1,1301 & 0,5266 \\
\hline & & $\begin{array}{l}\text { Nepenthes reinwardtiana } \\
\text { kantong merah }\end{array}$ & 1,7124 & 0,8914 & 1,1728 & 0,5326 \\
\hline \multirow[t]{2}{*}{2.} & \multirow[t]{2}{*}{ Kersik Mencege } & Nepenthes ampurella & 3,1611 & 0,9471 & 1,0842 & 0,6518 \\
\hline & & $\begin{array}{l}\text { Nepenthes gracilis kantong } \\
\text { Hijau }\end{array}$ & 5,1919 & 0,8833 & 1,1856 & 0,9166 \\
\hline \multirow[t]{2}{*}{3.} & \multirow[t]{2}{*}{ Kersik Serai } & $\begin{array}{l}\text { Nepenthes gracilis kantong } \\
\text { Hijau }\end{array}$ & 1,4738 & 0,9452 & 1,0871 & 0,5227 \\
\hline & & $\begin{array}{l}\text { Nepenthes Gracilis kantong } \\
\text { merah }\end{array}$ & 1,7778 & 0,86 & 1,2227 & 0,5338 \\
\hline
\end{tabular}


Selain adanya pengaruh faktor lingkungan dimana Nepenthes tumbuh, hasil tersebut relevan dengan kesimpulan Barbour et al. (1987) bahwa pola distribusi spesies tumbuhan cenderung menyebar kelompok, sebab tumbuhan bereproduksi dengan biji yang jatuh dekat dengan induknya atau rimpang yang menghasilkan anakan vegetatif yang masih dekat dengan induknya. Lebih jauh Indriyanto (2006) menyatakan bahwa pola penyebaran mengelompok adalah pola yang paling sering diamati dan merupakan gambaran utama bagi makhluk hidup karena telah memenangkan lingkungannya.
Nearest Neighbor Analysis atau analisa tetangga terdekat adalah sebuah analisis untuk menentukan suatu pola penyebaran vegetasi. Dengan menggunakan perhitungan analisis tetangga terdekat, maka penyebaran vegetasi dapat diketahui polanya yaitu mengelompok, tersebar atau seragam.

Dari pengolahan data dengan menggunakan tool ArcGis terhadap sebaran kantong semar (Nepenthes spp.) di Cagar Alam Padang Luway untuk lokasi 1 (Kersik Luway) dengan menggunakan Nearest Neighbor Analysis diperoleh hasil sebagaimana disajikan pada gambar 5 dan gambar 6 di bawah ini

\subsection{Nearest Neighbor Analysis}

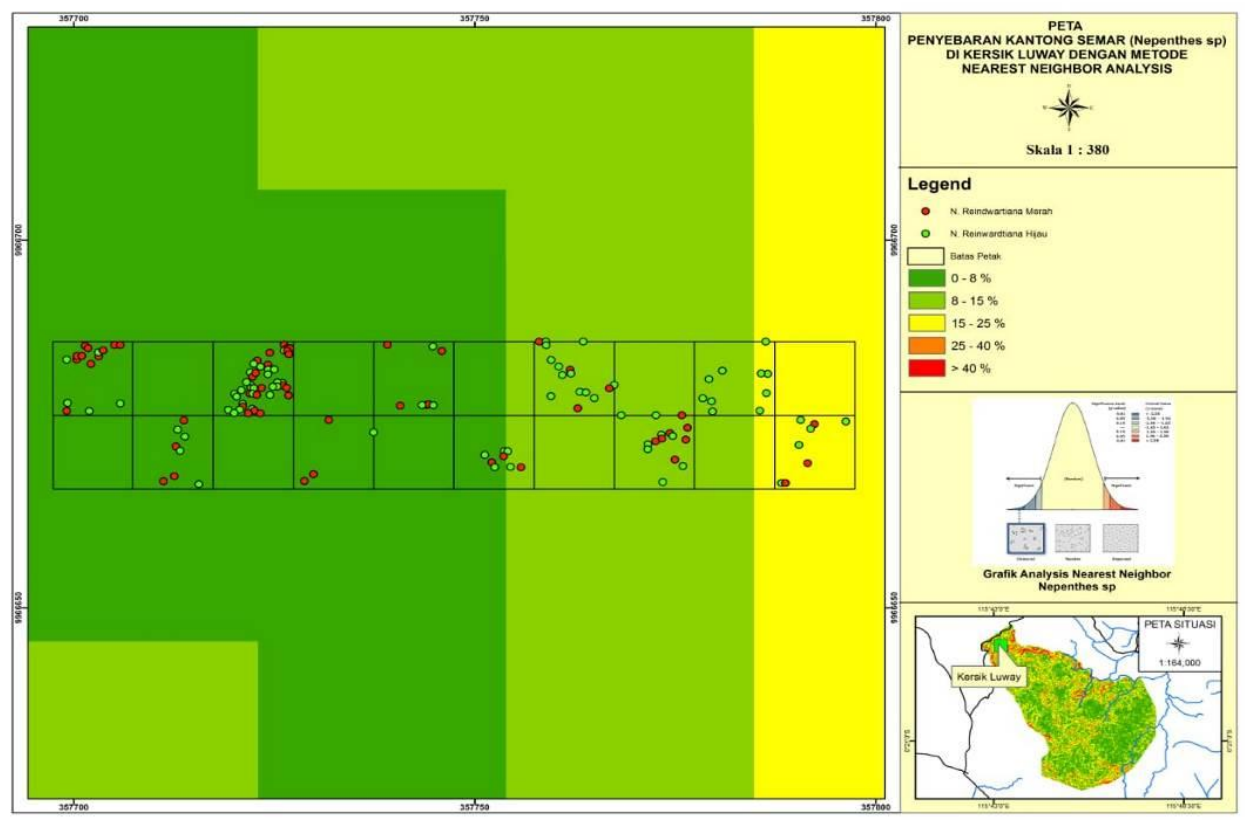

Gambar 5. Peta Penyebaran Nepenthes spp. di Kersik Luway dengan metode Nearest Neighbor Analysis 


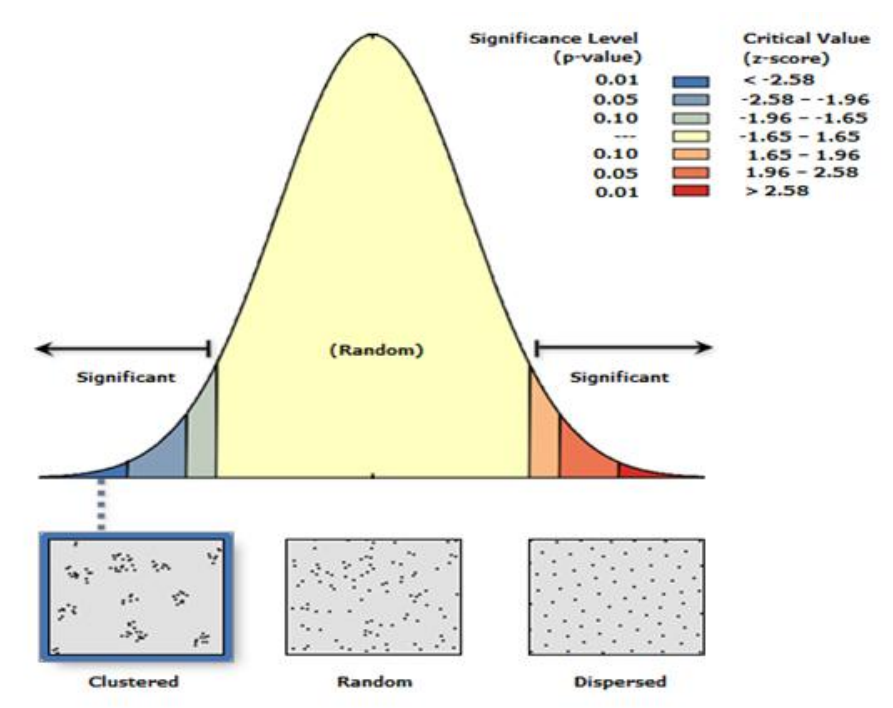

Gambar 6. Grafik Penyebaran Nepenthes spp. di Kersik Luway Dengan Metode Nearest Neighbor Analysis

Dari gambar dan grafik di atas diketahui bahwa pola penyebaran Nepenthes di lokasi Kersik Luway tersebar secara mengelompok (Clustered) dengan Nearest Neighbor Ratio $<1$ yaitu 0,649149 dan nilai z-score sebesar 7.884841 .

Hasil pengolahan data dengan menggunakan tool ArcGis terhadap sebaran kantong semar (Nepenthes spp.) di Cagar Alam Padang Luway dilokasi lainnya yaitu lokasi 2 (Kersik Mencege) maupun Lokasi 3 (Kersik Seray), menunjukan pola penyebaran mengelompok (Cluster) dengan nilai Nearest Neighbor Ratio $<1$ yaitu 0,528873 dan nilai z-score sebesar 11.923064 untuk lokasi Kersik Mencege dan nilai Nearest Neighbor Ratio $<1$ yaitu 0,397590 dengan nilai $z$-score sebesar -14668239 untuk lokasi 3 (Kersik Seray).

\section{KESIMPULAN}

Sebaran atau distribusi Nepenthes spp. di Cagar Alam Padang Luway dengan menggunakan indeks Morisita adalah cenderung mengelompok. Sedangkan sebaran spasial Nepenthes spp. di Cagar Alam Padang Luway dengan menggunakan Point Pattern Analysis : Nearest Neighbor Analysis adalah Cluster/mengelompok.

Potensi dan komposisi spesies Nepenthes spp. dan dominasinya di Cagar Alam Padang Luway dengan menggunakan metode analisa vegetasi diketahui bahwa INP tertinggi adalah Nepenthes gracilis kantong merah yaitu sebesar 58,420 \% dilokasi penelitian Kersik Serai, dan yang terendah adalah Nepenthes gracilis kantong hijau pada lokasi Kersik Mencege yaitu sebesar $15,953 \%$. Dengan demikian potensi terbesar Nepenthes spp. yang berada di CA. Padang Luway adalah dari jenis Nepenthes gracilis kantong merah.

\section{DAFTAR PUSTAKA}

Anonim, 2016. Nearest Neighbor Analysis, tersedia di link situs http://ceadserv1.nku.edu/longa//ge omed/ppa/doc/NNA/NNA.htm diakses pada tanggal 26 Mei 2019.

Barbour et al., 1987, Terrestrial Plant Ecology. Los Angeles: The 
Benyamin/Cummings Publishing Company. Inc.

Clarke C. 1997. Nepenthes of Borneo. Kinibalu, Sabah: Natural History Publications

Indriyanto, 2006. Ekologi Hutan. PT Bumi Aksara. Jakarta.

Dariana, 2010, Keanekaragaman Nepenthes dan Pohon Inang di Taman Wisata Alam Sicikehcikeh Kabupaten Dairi Sumatera Utara, USU.

Jongjitvimol, 2005. Nest Dispersion of Stingless Bee Species, Trigona collina Smith, 1857 (Apidae, Meliponinae) in a Mixed Deciduous Forest inThailand. The Natural History Journal of Chulalongkorn University 5(2) : 69-71.
Mansur, 2006. Nepenthes Kantong Semar Unik. Penebar Swadaya. Jakarta.
Peraturan Pemerintah Nomor 7/1999 tentang Pengawetan Jenis Tumbuhan dan Satwa Liar.

Soegianto, 1994. Ekologi Kuantitatif : Metode Analisis Populasi dan Komunitas. Usaha Nasional. Surabaya. 